\title{
Apixaban and risk of myocardial infarction: meta-analysis of randomized controlled trials
}

\author{
Adrienn Tornyos • András Vorobcsuk • \\ Péter Kupó · Dániel Aradi · Dániel Kehl · \\ András Komócsi
}

Published online: 25 July 2014

(C) Springer Science+Business Media New York 2014

\begin{abstract}
The coagulation system contributes greatly to the evolution of myocardial infarction (MI). Anticoagulation may reduce the occurrence of MI as monotherapy or with concomitant use of aspirin. Activated factor X antagonists (anti$\mathrm{Xa)}$ and direct thrombin inhibitors have promising results in various indications in non-inferiority trials. However, results regarding their cardiovascular safety are heterogeneous. We systematically evaluated the risk of MI and mortality in patients receiving the new-generation oral anti-Xa agent apixaban. Electronic databases were searched to find prospective, randomized, controlled clinical trials (RCT) that evaluated the clinical impact of apixaban. Efficacy measures included frequency of MI, cardiovascular and overall mortality. Outcome parameters of RCTs were pooled with a random-effects model. Between January 2000 and December 2013, 12 RCTs comprising 54,054 patients were identified. Based on the pooled results, there was no increase in the risk of MI in patients treated with apixaban [odds ratio (OR) 0.90;
\end{abstract}

Adrienn Tornyos and András Vorobcsuk have contributed equally to the manuscript.

Electronic supplementary material The online version of this article (doi:10.1007/s11239-014-1096-z) contains supplementary material, which is available to authorized users.

A. Tornyos · A. Vorobcsuk · P. Kupó · A. Komócsi ( $)$

Department of Interventional Cardiology, Heart Institute,

University of Pécs, 13 Ifjúság u, Pécs 7624, Hungary

e-mail: komocsi.andras@pte.hu

D. Aradi

Department of Cardiology, Heart Center, Balatonfüred, Hungary

D. Kehl

Department of Statistics and Econometrics, Institute of Applied

Studies in Business and Economics, Faculty of Business and

Economics, University of Pécs, Pecs, Hungary
$95 \%$ confidence interval (CI) $0.77-1.05 ; p=0.17]$ compared to different controls. Cardiovascular and overall mortality with apixaban was comparable to the control groups (OR $0.88 ; 95 \%$ CI $0.72-1.06 ; p=0.18$, OR $0.89 ; 95 \%$ CI $0.77-1.03 ; p=0.11$, respectively). The pooled risk of major bleeding was lower in the apixaban treated groups (OR 0.84; $95 \%$ CI $0.62-1.12 ; p=0.23$ ) however this reached significant level only in subgroup analysis of trials with anticoagulant regimes in the control (OR 0.66; $95 \%$ CI $0.51-0.87$; $p=0.003)$. In a broad spectrum of patients and compared to different controls apixaban treatment was not associated with an increase in MI or mortality.

Keywords Myocardial infarction · Apixaban · Meta-analysis

\section{Introduction}

The coagulation system contributes greatly to the evolution of myocardial infarction (MI). Antiplatelet therapy plays an essential role in preventing ischemic events among patients undergoing percutaneous coronary intervention (PCI) and after acute coronary syndromes (ACS) [1]. However, thrombotic events in ACS are not completely plateletdependent and previous experience with warfarin suggested an incremental ischemic benefit when anticoagulation was applied in combination to aspirin [2]. Though the high rates of bleeding complications, the narrow therapeutic window with need for careful monitoring in addition to the frequent drug and food interactions offset the thrombotic benefits and questioned the clinical relevance of this approach. Novel oral anticoagulants (NOAC) including activated factor $\mathrm{X}$ antagonists (anti-Xa) and direct thrombin inhibitors have promising results in various 
indications in multiple non-inferiority trials. However, heterogeneous results were found regarding their cardiovascular safety. Specifically, analyses of trials that tested NOACs in various indications showed a signal for increased risk of MI with dabigatran but not with rivaroxaban [3, 4]. Apixaban is a highly selective, direct inhibitor of activated factor $\mathrm{X}$ that, based on the results of multiple trials in wide range of indications, became a promising alternative to vitamin $\mathrm{K}$ antagonists.

We therefore performed a systematic review and metaanalysis and evaluated the risk of MI and mortality in patients receiving apixaban.

\section{Methods}

Study inclusion criteria, endpoints

Our meta-analysis followed the preferred reporting items for systematic reviews and meta-analyses (PRISMA) statement [5].

The main criteria for inclusion in the analysis were to compare the clinical efficacy and/or safety of an anticoagulant protocol with apixaban in a prospective, randomized controlled clinical trial.

PubMed, www.clinicaltrials.gov and Scopus databases were searched for relevant articles published between January 2000 and December 2013 using a search strategy that combined text word and MeSH heading. The search string was "apixaban" OR "bms 562247" AND "((randomized clinical trial OR RCT)" OR "(myocardial infarction OR mortality))". Furthermore, we increased the search with the reference lists of the relevant studies and reviews, editorials, letters, and also relevant abstracts.

Studies that aimed to compare merely the biological efficacy of the anticoagulant protocol, trials not reporting the frequency of MI as well as non-randomized studies and registries were disregarded.

The primary efficacy endpoint of the analysis was the frequency of MI. Overall mortality and cardiovascular death were defined as secondary endpoints. As a safety measure, frequency of major and clinically relevant nonmajor bleeding complications has been evaluated. MI, cardiovascular death and major and clinically relevant nonmajor bleeding were defined according to the internal definitions of the studies. The endpoints of interest were collected until the longest follow-up available.

Data abstraction and analysis

Manuscript selection and data abstraction were done independently by three reviewers (AK, AT and AV). Disagreements were resolved by consensus. Statistical analysis was performed using the Review Manager 5.1.6 (Review Manager [RevMan] Version 5.1 Copenhagen: The Nordic Cochrane Centre, The Cochrane Collaboration, 2011.) software.

Considering that the included trials were done in populations with different cardiovascular risk and applied disparate drug doses with dissimilar treatment effects, resulting in a substantial inter-study variance we prespecified the assessment of the effect sizes with a random effect model. The reported event frequencies were used to calculate odds ratios with $95 \%$ CI. Heterogeneity was tested with a Chi square heterogeneity statistic for which a $p<0.2$ was considered potentially heterogeneous. Consistency was assessed by $\mathrm{I}^{2}$ statistic which describes the percentage of total variation across studies that is due to heterogeneity rather than due to chance. Inconsistency was described as low, moderate, and high, based on $\mathrm{I}^{2}$ values of 25,50 , and $75 \%$, respectively [6]. Rate control metaregression analysis was performed to examine the effect of the trials background risk for MI to the effect estimate related to the apixaban action. To study the relevance of publication bias, funnel plots were constructed plotting the trial results against their precision. Risk of bias was assessed by the built-in risk of bias tool of the review manager program. Prespecified subgroup analyses were performed among trials with different agents or placebo in the control arm. Sensitivity analysis was performed with fixed effect model, between phase 2 or 3 studies and according to the indication fields and the concomitant antiplatelet treatment. A $p \leq 0.05$ was considered statistically significant.

\section{Results}

Search results and study characteristics

Our search resulted in 212 citations. After the evaluation of abstracts, 34 potentially appropriate studies were found. Finally, 12 studies were selected for data extraction and analysis [7-18] (Online Resource 1). The included trials were prospective multicenter randomized trials and involved 54,054 patients. The main characteristics of the 12 trials are listed in Table 1. Enoxaparin and/or warfarin were the comparator drugs in seven trials $[7,9-11,15,17$, 18], four trials were placebo controlled $[12-14,16]$ and aspirin was the comparator in one trial [8]. Three studies included patients who required total knee replacement and one included hip replacement $[7,9,10,18]$. Two trials were preformed in patients after deep vein thrombosis (DVT) and/or pulmonary embolism (PE) [11, 12]. Three trials investigated stroke prophylaxis in atrial fibrillation with adjusted-dose warfarin as the comparator $[8,15,17]$. 


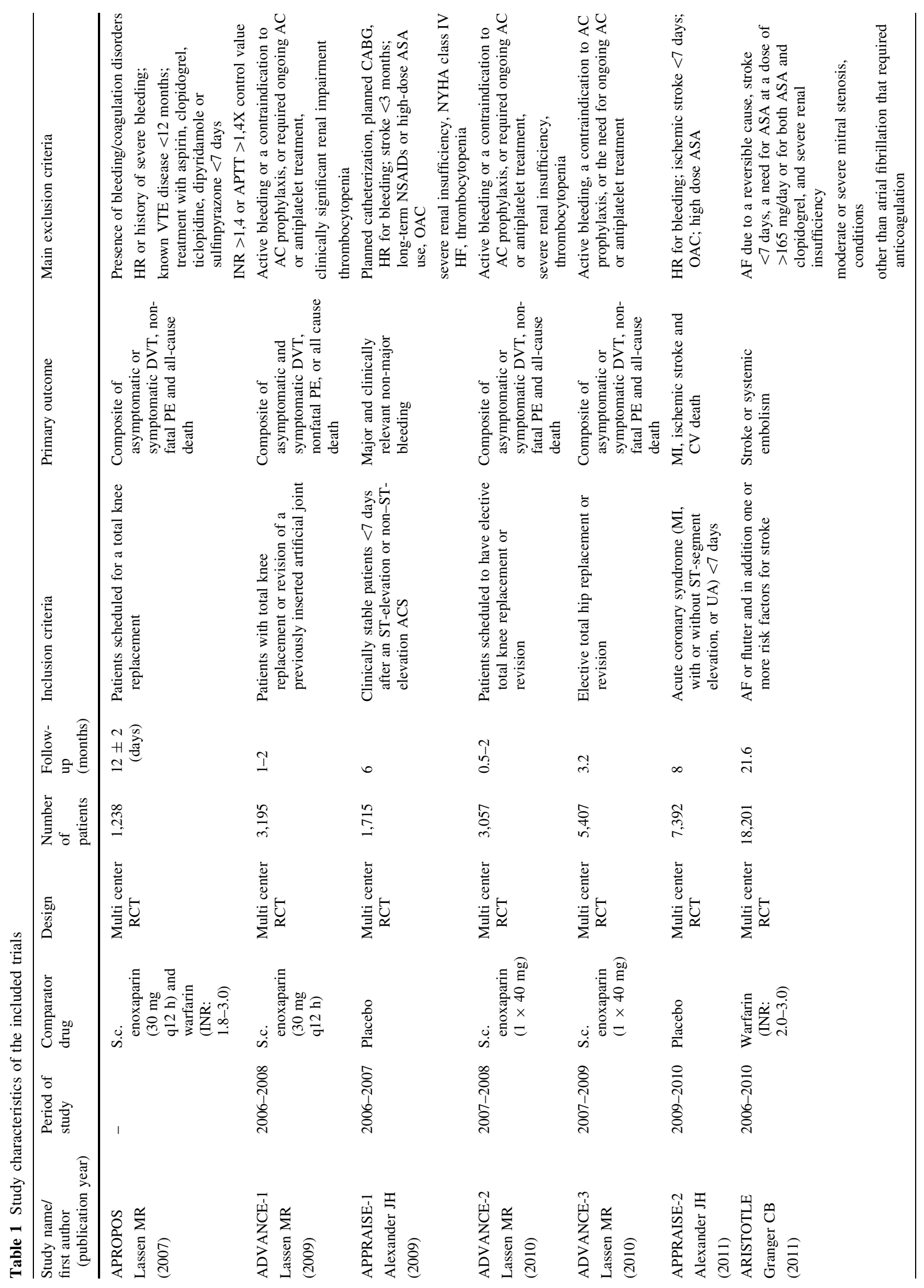




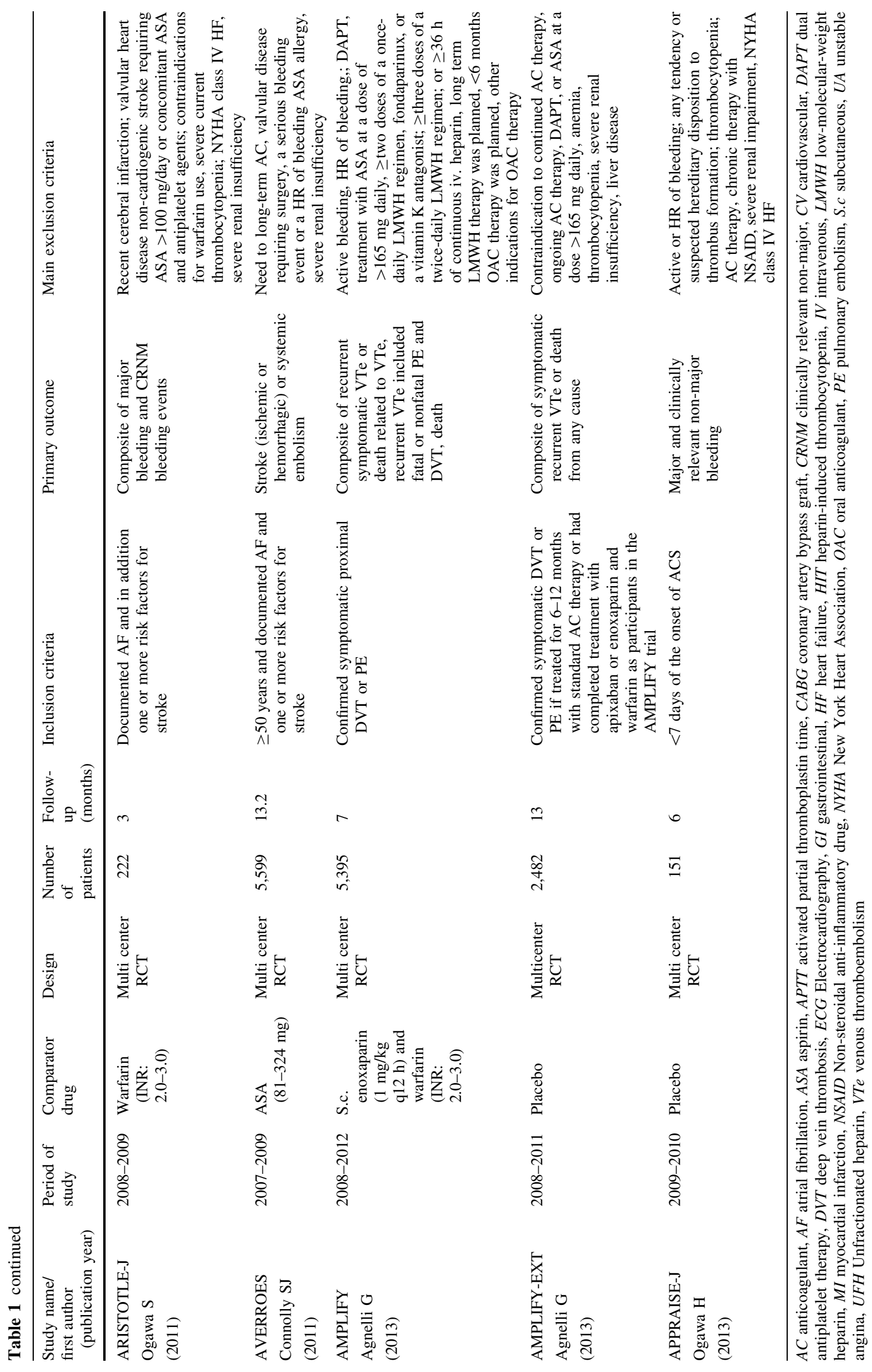


Three placebo controlled studies included patients after ACS $[13,14,16]$. Patients with concomitant antiplatelet therapy were excluded in eight trials. In the three ACS studies different proportions of patients were included after a coronary stent implantation and required concomitant use of dual antiplatelet therapy. In the APPRAISE-1 and APPRAISE-2 study the frequencies of PCI were 65.9 and $43.8 \%$ in the apixaban treated group and 64.8 and $44.2 \%$ in the control group, respectively $[13,14]$. In the APPRAISE-J study the frequency of PCI was $100 \%$ in the apixaban treated group and $98.1 \%$ in the control group. [16].

Follow-up varied from 12 days to 21.6 months. Completion of follow-up was greater than $95.7 \%$ in ten trials. (Table 2). The APPRAISE-2 and the APPRAISE-J trial were stopped prematurely [13, 16]. All studies were sponsored by the manufacturers of apixaban (Bristol-Myers Squibb and Pfizer). All trials were considered to be uniformly of high quality and analysis of funnel plots did not show signs of publication bias (data not shown).

Table 2 Patient and procedural characteristics of the included trials

\begin{tabular}{|c|c|c|c|c|c|c|c|c|c|c|}
\hline $\begin{array}{l}\text { Study name/first } \\
\text { author (publication } \\
\text { year) }\end{array}$ & Phase & $\begin{array}{l}\text { Mean } \\
\text { age } \\
\text { (year) }\end{array}$ & $\begin{array}{l}\text { Male } \\
(\%)\end{array}$ & $\begin{array}{l}\text { Obesity } \\
(\%)\end{array}$ & $\begin{array}{l}\mathrm{DM} \\
(\%)\end{array}$ & $\begin{array}{l}\text { Hypercholesterolaemia } \\
(\%)\end{array}$ & $\begin{array}{l}\text { Hypertension } \\
(\%)\end{array}$ & $\begin{array}{l}\text { Smoking } \\
(\%)\end{array}$ & $\begin{array}{l}\text { Hospitalization } \\
\text { (days) }\end{array}$ & $\begin{array}{l}\text { Lost to } \\
\text { follow-up } \\
\text { (\%) }\end{array}$ \\
\hline $\begin{array}{l}\text { APROPOS } \\
\text { Lassen MR } \\
(2007)\end{array}$ & 2 & $66.7 / 66.6$ & $36 / 38.7$ & - & - & - & - & - & $6 / 6$ & - \\
\hline $\begin{array}{l}\text { ADVANCE-1 } \\
\text { Lassen MR } \\
(2009)\end{array}$ & 3 & $65.9 / 65.7$ & $37.6 / 38.2$ & - & - & - & - & - & $6.3 / 6.4$ & - \\
\hline $\begin{array}{l}\text { APPRAISE-1 } \\
\text { Alexander JH } \\
(2009)\end{array}$ & 2 & $61 / 60$ & $76.8 / 74.3$ & - & $22.1 / 23.2$ & - & - & - & - & 1.4 \\
\hline $\begin{array}{l}\text { ADVANCE-2 } \\
\text { Lassen MR } \\
(2010)\end{array}$ & 3 & $67 / 67$ & $29 / 26$ & - & - & $89 / 88.3$ & - & - & $12 / 12$ & - \\
\hline $\begin{array}{l}\text { ADVANCE-3 } \\
\text { Lassen MR } \\
(2010)\end{array}$ & 3 & $60.9 / 60.6$ & $47.2 / 46.2$ & - & - & - & - & - & $9.3 / 9.2$ & 4.3 \\
\hline $\begin{array}{l}\text { APPRAISE-2 } \\
\text { Alexander JH } \\
(2011)\end{array}$ & 3 & $67 / 67$ & $67.4 / 68.3$ & - & $48.7 / 47$ & $83 / 84.2$ & - & - & - & 1.8 \\
\hline $\begin{array}{l}\text { ARISTOTLE } \\
\text { Granger CB } \\
(2011)\end{array}$ & 3 & $70 / 70$ & $64.5 / 65$ & - & $25 / 24.9$ & $45 / 45.1$ & $87.3 / 87.6$ & - & - & 1.1 \\
\hline $\begin{array}{l}\text { ARISTOTLE-J } \\
\text { Ogawa S } \\
(2011)\end{array}$ & 2 & $69.6 / 71.7$ & $83.8 / 81.1$ & - & $25 / 20.3$ & - & $82.4 / 85.1$ & - & - & - \\
\hline $\begin{array}{l}\text { AVERROES } \\
\text { Connolly SJ } \\
(2011)\end{array}$ & 3 & $70 / 70$ & $59 / 58$ & - & $19 / 20$ & $31 / 31$ & $86 / 87$ & - & - & - \\
\hline $\begin{array}{l}\text { AMPLIFY } \\
\text { Agnelli G } \\
(2013)\end{array}$ & 3 & $57.2 / 56.7$ & $58.3 / 59.1$ & $19.4 / 19.2$ & - & - & - & - & - & 0.3 \\
\hline $\begin{array}{l}\text { AMPLIFY-EXT } \\
\text { Agnelli G } \\
(2013)\end{array}$ & 3 & $56.5 / 57.1$ & $57.8 / 56.5$ & $27.3 / 26.4$ & $11.0 / 11.2$ & $30.5 / 29.1$ & $39.9 / 42.9$ & $18.4 / 19.1$ & - & 2.1 \\
\hline $\begin{array}{l}\text { APPRAISE-J } \\
\text { Ogawa H } \\
\text { (2013) }\end{array}$ & 2 & $64.9 / 63.9$ & $89.9 / 80.8$ & - & $34.3 / 50.0$ & - & - & - & - & 1.3 \\
\hline
\end{tabular}

Hypercholesterolaemia defined as hypercholesterolaemia and statin use

$D M$ diabetes mellitus 


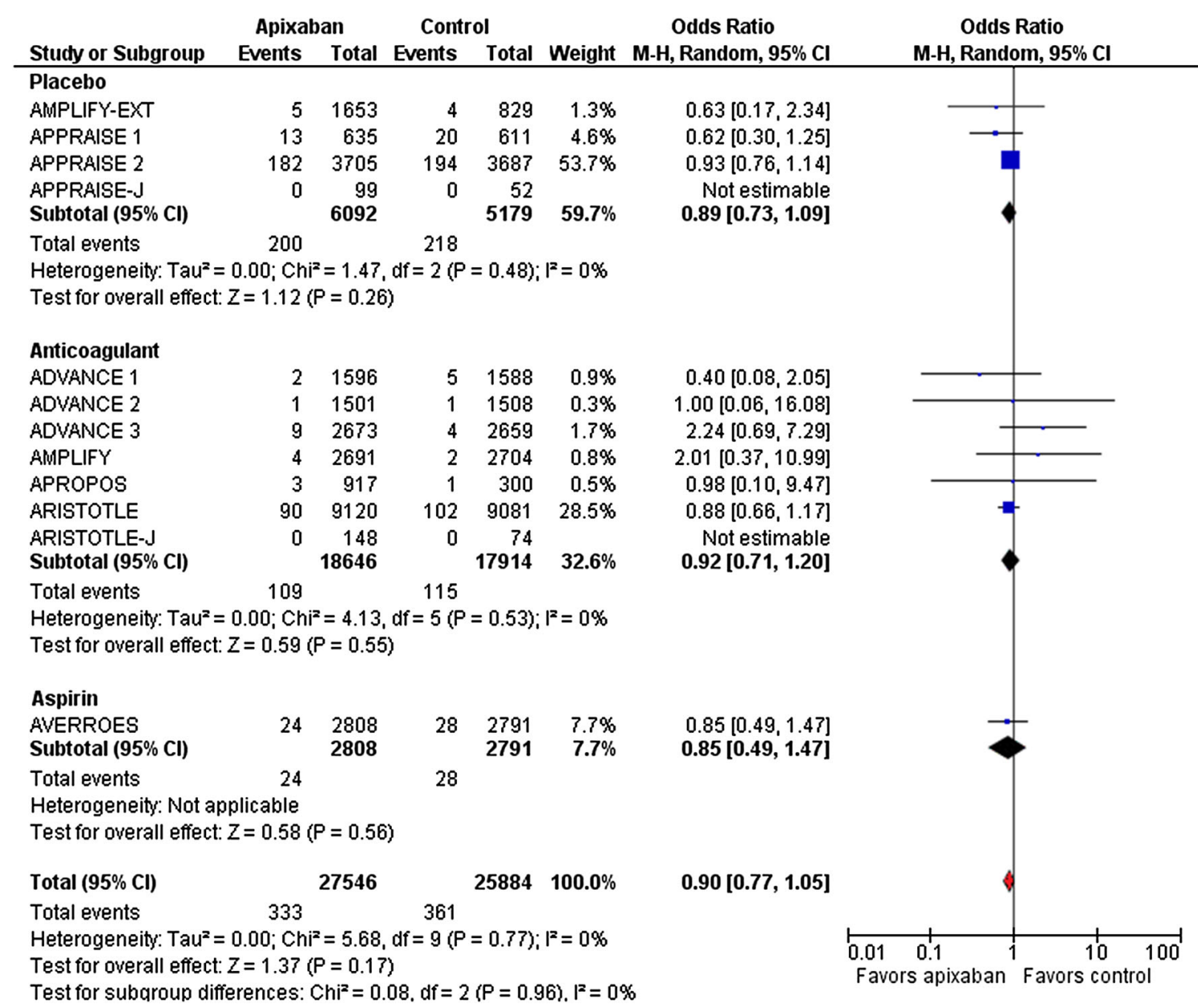

Fig. 1 Impact of apixaban on the frequency of myocardial infarction. Subgroup analyses were performed according to the randomized medications applied in the control groups

\section{Clinical results}

Based on the pooled results of the random-effects model meta-analysis, apixaban was not associated with higher risk for $\mathrm{MI}$ when tested against different comparators [(OR) 0.90 (95\% CI 0.77-1.05)] (Fig. 1). The cumulative mortality and rate of cardiovascular deaths were lower with apixaban, however this difference did not reach statistical significance [OR 0.89; $95 \%$ CI 0.76-1.03 and OR 0.88; $95 \%$ CI 0.72-1.06, respectively] (Fig. 2, Online Resource 2 ). The pooled risk of major bleeding was lower in the apixaban treated groups [OR $0.84 ; 95 \%$ CI 0.62-1.12), however, this difference reached significant level only in subgroup analysis of trials with anticoagulant regimes in the control (OR 0.66; $95 \%$ CI $0.51-0.87 ; p=0.003$ ). (Fig. 3). Rate control meta-regression analysis, however, did not show relation of background risk and the effect of apixaban regarding MI (Online Resource 3).

Data regarding the frequency of MI were consistent and homogenous. Cardiovascular mortality and overall mortality data showed low inconsistency, while data regarding major and clinically relevant non-major bleeding were inconsistent and heterogeneous in the included trials. Sensitivity analyses did not showed major difference from the above results. (Table 3 ).

\section{Discussion}

This meta-analysis involving 54,054 patients provides a comprehensive assessment of the risk of MI with a novel active $\mathrm{X}$ factor oral anticoagulant agent, apixaban in a broad spectrum of potential indications. The main finding of the analysis is that apixaban treatment is not associated with increased risk of MI. In fact, MI rate was numerically, however not significantly lower (1.22 vs. $1.39 \%$ ) among patients treated with apixaban. Similarly mortality data showed no increase with apixaban but a non-significant tendency for benefit. Altogether these data confirm cardiovascular safety of apixaban. 


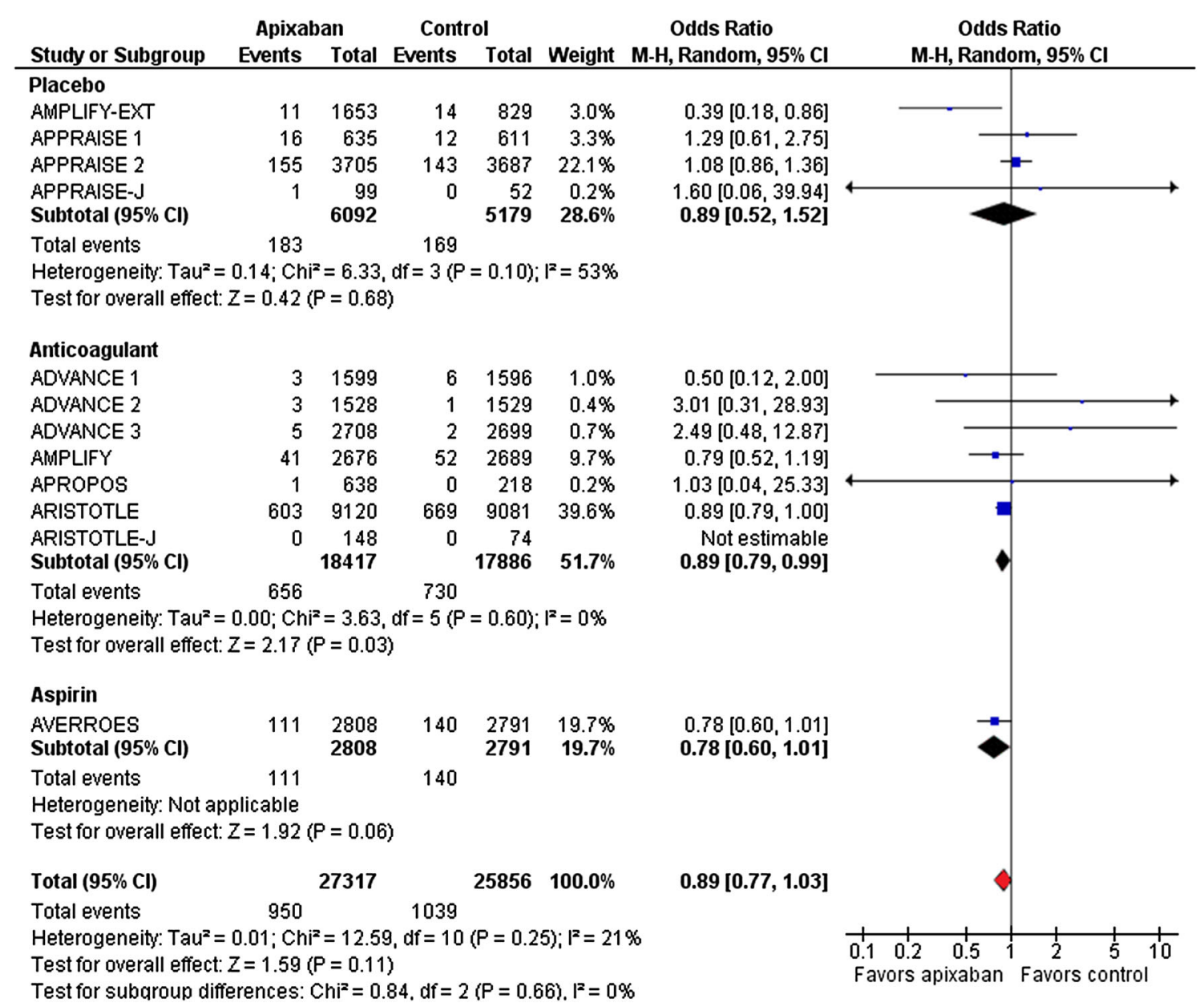

Fig. 2 Impact of apixaban on the overall mortality. Subgroup analyses were performed according to the randomized medications applied in the control groups

Earlier trials in various fields of prevention found antiplatelet and anticoagulant agents to be effective in preventing MI. However, due to the delicate balance of the potential benefit and the increased risk of bleeding recommendations greatly differ in different clinical situations regarding the use of these medications [1]. Antiplatelet therapy is essential in preventing ischemic events among patients undergoing PCI and after ACS, however, coronary thrombotic events are not completely platelet-dependent. Administration of warfarin in combination to aspirin in patients after an acute coronary event resulted in an incremental ischemic benefit. In a prior meta-analysis, therapeutic-range anticoagulation with warfarin [international ratio (INR) 2-3] was associated with a significant reduction of ischemic events [OR 0.73 (0.63-0.84), $p<0.0001]$ but triggered an increased risk of major bleeding [2]. Due to high rates of bleeding complications, the narrow therapeutic window with need for careful monitoring in addition to the frequent drug and food interactions, however, offset the thrombotic benefits and questioned the clinical relevance of routine combined therapy.

Recently, novel agents targeting the thrombin dependent anticoagulation pathways have emerged and multiple studies demonstrated their efficacy and better safety profile in various fields of thromboembolic prevention and treatment [7-13, 17-22]. Contrasting their success in stroke prevention, PE and DVT the new generation oral anticoagulants among patients after ACS were associated with a dramatic increase in bleeding events. In the ACS trials moderate reductions in the risk of stent thrombosis and composite ischemic events were observed while regarding effect on the frequency of MI the new generation oral anticoagulant agents showed heterogeneous results [23].

The concern about an increased risk of MI was raised first regarding dabigatran. This signal was present in the first publication of the "randomized evaluation of longterm anticoagulation therapy" (RE-LY) trial, there was a 


\begin{tabular}{|c|c|c|c|c|c|c|c|c|}
\hline Study or Subgroup & \multicolumn{2}{|c|}{ Apixaban } & \multicolumn{2}{|c|}{ Control } & Weight & $\begin{array}{c}\text { Odds Ratio } \\
\text { M-H, Random, } 95 \% \mathrm{Cl}\end{array}$ & \multicolumn{2}{|c|}{$\begin{array}{c}\text { Odds Ratio } \\
\text { M-H, Random, } 95 \% \mathrm{Cl}\end{array}$} \\
\hline \multicolumn{9}{|l|}{ Placebo } \\
\hline AMPLIFY-EXT & 62 & 1653 & 22 & 829 & $9.7 \%$ & $1.43[0.87,2.34]$ & & \\
\hline APPRAISE 1 & 3 & 630 & 18 & 599 & $4.0 \%$ & $0.15[0.05,0.53]$ & & \\
\hline APPRAISE 2 & 46 & 3705 & 18 & 3687 & $9.2 \%$ & $2.56[1.48,4.43]$ & & $\rightarrow$ \\
\hline $\begin{array}{l}\text { APPRAISE-J } \\
\text { Subtotal }(95 \% \mathrm{Cl})\end{array}$ & 4 & $\begin{array}{r}98 \\
6086\end{array}$ & 1 & $\begin{array}{r}51 \\
5166\end{array}$ & $\begin{array}{r}1.6 \% \\
24.5 \%\end{array}$ & $\begin{array}{r}2.13[0.23,19.55] \\
\mathbf{1 . 0 8}[0.40,2.98]\end{array}$ & & \\
\hline \multicolumn{9}{|c|}{$\begin{array}{l}\text { Heterogeneity: } \mathrm{Tau}^{2}=0.76 ; \mathrm{Chi}^{2}=17.25, \mathrm{df}=3(\mathrm{P}=0.0006) ; \mathrm{I}^{2}=83 \% \\
\text { Test for overall effect: } Z=0.16(P=0.87)\end{array}$} \\
\hline \multicolumn{9}{|l|}{ Anticoagulant } \\
\hline ADVANCE 1 & 46 & 1596 & 68 & 1588 & $10.9 \%$ & $0.66[0.45,0.97]$ & $\rightarrow$ & \\
\hline ADVANCE 2 & 53 & 1501 & 72 & 1508 & $11.1 \%$ & $0.73[0.51,1.05]$ & $\rightarrow$ & \\
\hline ADVANCE 3 & 129 & 2673 & 134 & 2659 & $12.2 \%$ & $0.96[0.75,1.22]$ & & \\
\hline AMPLIFY & 115 & 2691 & 261 & 2704 & $12.4 \%$ & $0.42[0.33,0.52]$ & - & \\
\hline APROPOS & 18 & 917 & 0 & 300 & $1.0 \%$ & $12.36[0.74,205.73]$ & & \\
\hline ARISTOTLE & 613 & 9088 & 877 & 9052 & $13.1 \%$ & $0.67[0.61,0.75]$ & - & \\
\hline $\begin{array}{l}\text { ARISTOTLE-J } \\
\text { Subtotal }(95 \% \mathrm{Cl})\end{array}$ & 2 & $\begin{array}{r}143 \\
18609\end{array}$ & 4 & $\begin{array}{r}75 \\
17886\end{array}$ & $\begin{array}{r}2.4 \% \\
63.3 \%\end{array}$ & $\begin{array}{l}0.25[0.05,1.41] \\
\mathbf{0 . 6 6}[0.51,0.87]\end{array}$ & & \\
\hline \multicolumn{9}{|c|}{$\begin{array}{l}\text { Heterogeneity: } \text { Tau }^{2}=0.08 ; \mathrm{Chi}^{2}=30.06, \mathrm{df}=6(\mathrm{P}<0.0001) ; \mathrm{I}^{2}=80 \% \\
\text { Test for overall effect: } Z=2.93(\mathrm{P}=0.003)\end{array}$} \\
\hline \multicolumn{9}{|l|}{ Aspirin } \\
\hline $\begin{array}{l}\text { AVERROES } \\
\text { Subtotal }(95 \% \mathrm{Cl})\end{array}$ & 140 & $\begin{array}{l}2808 \\
2808\end{array}$ & 123 & $\begin{array}{l}2791 \\
2791\end{array}$ & $\begin{array}{l}12.2 \% \\
12.2 \%\end{array}$ & $\begin{array}{l}1.14[0.89,1.46] \\
\mathbf{1 . 1 4}[0.89, \mathbf{1 . 4 6}]\end{array}$ & & \\
\hline \multicolumn{9}{|c|}{$\begin{array}{l}\text { Heterogeneity: Not applicable } \\
\text { Test for overall effect: } Z=1.02(P=0.31)\end{array}$} \\
\hline Total $(95 \% \mathrm{Cl})$ & & 27503 & & 25843 & $100.0 \%$ & $0.84[0.62,1.12]$ & 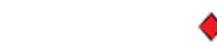 & 正 \\
\hline Total events & 1231 & & 1598 & & & & & \\
\hline $\begin{array}{l}\text { Heterogeneity: Tau } \\
\text { Test for overall effect } \\
\text { Test for subaroup dif }\end{array}$ & $\begin{array}{l}0.17 ; \mathrm{Chi} \\
\mathrm{Z}=1.19( \\
\text { erences: }\end{array}$ & $\begin{array}{l}=82.31 \\
P=0.23 \\
C h i^{2}=8\end{array}$ & $\begin{array}{l}1, d f=11 \\
30, d f=2\end{array}$ & $(P<0.00$ & $10001)\left._{i}\right|^{2}=$ & $=87 \%$ & $\begin{array}{cc} & 1 \\
0.01 & 0.1 \\
\text { Favors apixaban }\end{array}$ & $\begin{array}{l}10 \\
1 \\
\text { Favors cor }\end{array}$ \\
\hline
\end{tabular}

Fig. 3 Impact of apixaban on the frequency of major and clinically relevant non-major bleeding. Subgroup analyses were performed according to the randomized medications applied in the control groups

higher incidence of MI with dabigatran (hazard ratio 1.38; $95 \%$ CI $1.00-1.91 ; p<0.048$ ) [19]. A subsequently performed, repeated analysis suggested lack of significant difference; however, was in contrasts with a meta-analysis of seven trials of dabigatran that showed a significantly higher risk of MI [4, 24, 25]. The underlying mechanisms of this finding are not clear. As a member of the same class ximelagatran was found to increase some proinflammatory markers it has been hypothesized that dabigatran might have effects that are unfavorable to atherosclerosis or atherosclerotic thrombotic events [4]. Of note that the use of ximelagatran resulted in reduction of MI events in the ESTEEM trial conducted among patients with recent ACS that makes the probability of a real class effect debatable [26].

Rivaroxaban was the first available orally active direct factor Xa inhibitor. In Europe and in the USA it was approved for use in prevention of stroke and systemic embolism, in patients with non-valvular atrial fibrillation and for treatment of deep venous thromboembolism. It was also approved for prevention of recurrent deep venous thromboembolism and PE. Contrary to dabigatran, analysis of the phase two and three trials showed reduction of MI with rivaroxaban [3]. Of note, in patients after a reduced dose $(2.5 \mathrm{mg}$ twice daily in combination with standard antiplatelet therapy) of rivaroxaban resulted in reduction of ischemic events as well as in improved survival in the antiXa therapy to lower cardiovascular events in addition to standard therapy in subjects with acute coronary syndrome-thrombolysis in myocardial infarction 46 (ATLAS ACS 2-TIMI 51) trial compared to placebo [27]. Among the new generation oral anticoagulants this was the only phase three trial among ACS showing a statistically significant benefit. As a possible explanation it has been hypothesized that thrombin may have a dose dependent balance among its anticoagulant and procoagulant action, and at low dose rivaroxaban may more effectively affected the latter. The facts, however, that among different doses of rivaroxaban frequencies of ischemic and bleeding events were parallel doubt this assumption and the reason for the 
Table 3 Sensitivity analyses

\begin{tabular}{lllll}
\hline & \multicolumn{2}{l}{ Odds ratio (95\% confidence interval) } & & \\
\cline { 2 - 5 } & $\begin{array}{l}\text { Number of studies } \\
\text { (number of patients) }\end{array}$ & $\begin{array}{l}\text { Myocardial } \\
\text { infarction }\end{array}$ & $\begin{array}{l}\text { Cardiovascular } \\
\text { mortality }\end{array}$ & $\begin{array}{l}\text { Overall } \\
\text { mortality }\end{array}$ \\
\hline Fixed effect model & $12(54,054)$ & $0.90[0.77-1.05]$ & $0.89[0.77-1.02]$ & $0.90[0.82-0.98]^{*}$ \\
Phase 3 trials & $6(50,728)$ & $0.92[0.78-1.07]$ & $0.84[0.68-1.05]$ & $0.87[0.73-1.03]$ \\
Phase 2 trials & $4(3,326)$ & $0.64[0.33-1.26]$ & $1.33[0.62-2.86]$ & $1.29[0.63-2.64]$ \\
AMPLIFY excluded & $11(48,659)$ & $0.89[0.77-1.04]$ & $0.89[0.73-1.08]$ & $0.90[0.76-1.06]$ \\
AMPLIFY-EXT excluded & $11(51,572)$ & $0.90[0.78-1.05]$ & $0.91[0.79-1.05]$ & $0.90[0.83-0.99]^{*}$ \\
$\begin{array}{l}\text { Non-valvular atrial fibrillation trials } \\
\text { Acute coronary syndrome trials }\end{array}$ & $3(24,022)$ & $0.87[0.68-1.12]$ & $0.88[0.74-1.05]$ & $0.87[0.78-0.97]^{* *}$ \\
Thrombosis prophylaxis after major & $3(9,258)$ & $0.88[0.66-1.16]$ & $0.99[0.77-1.28]$ & $1.1[0.88-1.37]$ \\
$\quad$ orthopedic surgery trials & $4(12,897)$ & $1.18[0.51-2.74]$ & - & $1.18[0.47-2.96]$ \\
$\begin{array}{l}\text { DVT or PE treatment trials } \\
\text { Trials that excluding patients with APT }\end{array}$ & $2(7,877)$ & $0.99[0.32-3.02]$ & $0.31[0.13-0.71]^{* *}$ & $0.60[0.31-1.18]$ \\
$\begin{array}{l}\text { Trials excluding patient with high dose ASA } \\
\quad>100 \text { mg/day or }>165 \text { mg/day) or DAPT }\end{array}$ & $4(26,300)$ & $1.18[0.51-2.74]$ & No evaluated & $1.21[0.51-2.82]$ \\
$\begin{array}{l}\text { Trials not excluding patients with APT } \\
\text { Events during the follow up period excluded }\end{array}$ & $4(14,857)$ & $0.88[0.67-1.16]$ & $0.52[0.22-1.26]$ & $0.87[0.78-0.97]^{* *}$ \\
\hline
\end{tabular}

$A S A$ aspirin, $A P T$ antiplatelet therapy, $D A P T$ dual antiplatelet therapy, $D V T$ deep vein thrombosis, $P E$ pulmonary embolism

discrepancy remains unclear [27]. Based on the above data rivaroxaban was approved in Europe but not in the USA in patient after recent ACS.

Apixaban a direct factor Xa inhibitor has been available in Europe since May 2011 and was approved for preventing venous thromboembolism after elective hip or knee replacement. The FDA approved apixaban in december 2012 with an indication of reducing the risk of stroke and systemic embolism in patients with non-valvular atrial fibrillation. Unlike rivaroxaban, apixaban trials were not successful in preventing ischemic events in patients after a recent episode of ACS. Specifically the phase 3 ACS trial [apixaban for prevention of acute ischemic events 2 (APPRAISE-2)] was prematurely stopped, owing to an excess of clinically important bleeding events with apixaban in the absence of a counterbalancing reduction in ischemic events [13]. The main duration of the follow-up from the time of randomization was 240 in the apixaban and 242 day in the placebo arm, compared to the planned 1.25 years, with a median exposure to the drug 175 days, however, during this period 572 primary events were encountered i.e. more than $60 \%$ of the initially planned number. Even if the increase in bleeding led more frequently to discontinuation of the study drug and resulted in the termination of the trial that limit the certainty of the conclusions that can be drawn about efficacy the lack of ischemic benefit raised serious concerns regarding the use of apixaban together with antiplatelet drugs. In fact the APPRAISE-2 trial did not show signal for increase in coronary events but regarding the efficacy endpoints in this trial apixaban reduced the rate of stent thrombosis from 1.3 to $0.9 \%$ (OR $0.7395 \%$ CI $0.47-1.12$ ) and the rate of MI was also lower. (Fig. 1). Unfortunately, we lack trials performed with low dose apixaban in patients with ACS. This leaves the question unanswered as to whether low dose treatment as with rivaroxaban would result in similar improvement with apixaban.

It should be acknowledged that there might be specific differences regarding the risk of MI altering with clinical situations, and different control medications. Rate control meta-regression analysis of the effect on MI frequency, however, did not showed signal for such confounder (Online resource 3). Moreover, the data were homogenous across the different control groups, supporting the robustness of the findings.

Some limitations to our analysis should be acknowledged. In order to comprehensiveness we included phase 2, explorative and dose finding trials. Albeit these may have introduced different risk and benefit effects in the analysis the sensitivity analysis including only phase three trials found similar results to that of the comprehensive analysis. There was a $23 \%$ of overlap between the patient population of the AMPLIFY and the AMPLIFY-EXT trials. To correct for this sensitivity analyses with exclusion each of these trials were performed that do no resulted in divergent results from the overall analysis. (Table 3). Regarding the risk of MI, it very important to note that most studies showed less than ten events per 
group representing a very low risk population. Most of events were observed in only two studies: APRAISE-2 and ARISTOTLE. In addition the APRAISE-2 study has been stopped early because of safety concern with apixaban. Hence, main limitation of our meta-analysis is that none of the included trials had MI defined as primary endpoint nor was adequately powered for this individual end-point. Although we tried to achieve a comprehensive overview of apixaban trials during the data capture three trials (study of apixaban for the prevention of thrombosisrelated events in patients with acute medical illness (ADOPT), a phase 2 pilot study of apixaban for the prevention of thromboembolic events in patients with advanced (metastatic) cancer and the Boticelli-DVT doseranging study) had to be excluded because lack of reporting the frequency of MI. In order to gain information regarding the longest available follow-up in our analysis events from the treatment periods and the followup periods of the trials were included. Sensitivity analysis with including events only during the treatment periods showed no differences from the comprehensive analysis. Also there are a number of studies with premature termination and short follow-up in this field. Consequently to these limitations, results of the cumulative analysis may not be regarded as definitive and can be interpreted only as hypothesis generating data.

In conclusion meta-analysis of trials performed in a broad spectrum of patients and compared against different controls apixaban treatment was not associated with increase of the rate of MI. Our current analysis extended the earlier findings with reassuring the cardiovascular safety of apixaban.

Acknowledgments The research was supported by the Hungarian Scientific Research Funds [83464 to A.K.].

Conflict of interest The authors report no conflicts of interest.

\section{References}

1. Perk J, De Backer G, Gohlke H, Graham I, Reiner Ž, Verschuren M, Baigent C (2012) European Guidelines on cardiovascular disease prevention in clinical practice (version 2012). The fifth joint task force of the european society of cardiology and other societies on cardiovascular disease prevention in clinical practice (constituted by representatives of nine societies and by invited experts) developed with the special contribution of the european association for cardiovascular prevention \& rehabilitation (EACPR). Eur Heart J 33(13): 1635-1701

2. Andreotti F, Testa L, Biondi-Zoccai GG, Crea F (2006) Aspirin plus warfarin compared to aspirin alone after acute coronary syndromes: an updated and comprehensive meta-analysis of 25,307 patients. Eur Heart J 27:519-526

3. Chatterjee S, Sharma A, Uchino K et al (2013) Rivaroxaban and risk of myocardial infarction: insights from a meta-analysis and trial sequential analysis of randomized clinical trials. Coron Artery Dis 24:628-635

4. Uchino K, Hernandez, AV (2012) Dabigatran association with higher risk of acute coronary events: meta-analysis of noninferiority randomized controlled trials. Arch Intern Med 172:397-402

5. Moher D, Liberati A, Tetzlaff J, Altman DG (2009) Preferred reporting items for systematic reviews and meta-analyses: the PRISMA statement. Ann Intern Med 151:264-269

6. The Nordic Cochrane Centre: Review Manager (RevMan) (2011)

7. Lassen MR, Gallus A, Raskob GE et al (2010) Apixaban versus enoxaparin for thromboprophylaxis after hip replacement. N Engl J Med 363:2487-2498

8. Connolly SJ, Eikelboom J, Joyner C et al (2011) Apixaban in patients with atrial fibrillation. N Engl J Med 364:806-817

9. Lassen MR, Raskob GE, Gallus A et al (2010) Apixaban versus enoxaparin for thromboprophylaxis after knee replacement (ADVANCE-2): a randomised double-blind trial. Lancet 375:807-815

10. Lassen MR, Raskob GE, Gallus A et al (2009) Apixaban or enoxaparin for thromboprophylaxis after knee replacement. N Engl J Med 361:594-604

11. Agnelli G, Buller HR, Cohen A et al (2013) Oral apixaban for the treatment of acute venous thromboembolism. N Engl J Med 369:799-808

12. Agnelli G, Buller HR, Cohen A et al (2013) Apixaban for extended treatment of venous thromboembolism. N Engl J Med 368:699-708

13. Alexander JH, Lopes RD, James S et al (2011) Apixaban with antiplatelet therapy after acute coronary syndrome. N Engl J Med 365:699-708

14. Alexander JH, Becker RC, Bhatt DL et al (2009) Apixaban, an oral, direct, selective factor Xa inhibitor, in combination with antiplatelet therapy after acute coronary syndrome: results of the apixaban for prevention of acute ischemic and safety events (APPRAISE) trial. Circulation 119:2877-2885

15. Ogawa S, Shinohara Y, Kanmuri K (2011) Safety and efficacy of the oral direct factor xa inhibitor apixaban in japanese patients with non-valvular atrial fibrillation. The ARISTOTLE-J study. Circ J 75:1852-1859

16. Ogawa H, Goto S, Matsuzaki M, Hiro S, Shima D (2013) Randomized, double-blind trial to evaluate the safety of apixaban with antiplatelet therapy after acute coronary syndrome in Japanese patients (APPRAISE-J). Circ J 77:2341-2348

17. Granger CB, Alexander JH, McMurray JJ et al (2011) Apixaban versus warfarin in patients with atrial fibrillation. $\mathrm{N}$ Engl $\mathrm{J}$ Med 365:981-992

18. Lassen MR, Davidson BL, Gallus A et al (2007) The efficacy and safety of apixaban, an oral, direct factor Xa inhibitor, as thromboprophylaxis in patients following total knee replacement. J Thromb Haemost 5:2368-2375

19. Connolly SJ, Ezekowitz MD, Yusuf S et al (2009) Dabigatran versus warfarin in patients with atrial fibrillation. $\mathrm{N}$ Engl $\mathrm{J}$ Med 361:1139-1151

20. Burness CB, Perry CM (2014) Rivaroxaban: a review of its use in the treatment of deep vein thrombosis or pulmonary embolism and the prevention of recurrent venous thromboembolism. Drugs 74(2):243-262

21. Patel MR, Mahaffey KW, Garg J et al (2011) Rivaroxaban versus warfarin in nonvalvular atrial fibrillation. $\mathrm{N}$ Engl $\mathrm{J}$ Med 365:883-891

22. Giugliano RP, Ruff CT, Braunwald E et al (2013) Edoxaban versus warfarin in patients with atrial fibrillation. $\mathrm{N}$ Engl $\mathrm{J}$ Med 369:2093-2104

23. Komocsi A, Vorobcsuk A, Kehl D, Aradi D (2012) Use of newgeneration oral anticoagulant agents in patients receiving antiplatelet therapy after an acute coronary syndrome: systematic 
review and meta-analysis of randomized controlled trials. Arch Intern Med 172:1537-1545

24. Hohnloser SH, Oldgren J, Yang S, Wallentin L, Ezekowitz M, Reilly P, Connolly SJ (2012) Myocardial ischemic events in patients with atrial fibrillation treated with dabigatran or warfarin in the RE-LY (randomized evaluation of long-term anticoagulation therapy) trial. Circulation 125:669-676

25. Connolly SJ, Ezekowitz MD, Yusuf S, Reilly PA, Wallentin L (2010) Newly identified events in the RE-LY trial. N Engl J Med 363:1875-1876
26. Artang R, Rome E, Nielsen JD, Vidaillet HJ (2013) Meta-analysis of randomized controlled trials on risk of myocardial infarction from the use of oral direct thrombin inhibitors. Am J Cardiol 112:1973-1979

27. Mega JL, Braunwald E, Wiviott SD et al (2012) Rivaroxaban in patients with a recent acute coronary syndrome. N Engl J Med 366:9-19 